\title{
Continuing professional development and ICT: target practice
}

\author{
K. A. Eaton ${ }^{1}$ and P. A. Reynolds ${ }^{2}$
}

IN BRIEF

- Considers the impact of ICT on dental postgraduate and continuing professional education in the UK.

- Reviews the existing and potential future contributions that ICT is making in these areas of dental education.

- Explores the need for teachers to develop new skills to fully exploit the uses of ICT.

- An increasing proportion of dental education will be delivered through ICTbased distance learning.

Ever-increasing needs and demands by dentists and all other members of the dental team for education and training at all levels - undergraduate, postgraduate and continuing - are straining the resources of existing providers of such education. At the same time, there are ever-increasing opportunities to develop online delivery and the use of a range of information and communication technology (ICT) systems and services further, in all aspects of dental education. This paper reviews recent developments that have led to an increased demand for dental postgraduate programmes and continuing professional development (CPD) courses in the United Kingdom and then discusses how ICT has and will impact on teaching practice. Examples include the use of teaching and learning resources in a virtual learning environment (VLE) and the increasing use of blended learning. The paper then explores the need for both teachers and students to adapt to the new environment to ensure they can benefit to the maximum and that teaching and learning practices are changed accordingly.

\section{E-LEARNING IN DENTISTRY}

Section A: Teaching and technology

1. A description of the new technologies used in transforming dental education

2. Seeing is believing: dental education benefits from developments in videoconferencing

3. Webcasting: casting the web more widely

4. Top of the pops - CD-ROM and DVDs in dental education

Section B: Informatics: better informed by systems and services

5. Better informed: an overview of health informatics

6. Better informed in clinical practice a brief overview of dental informatics

7. Digital clinical records and practice administration in primary dental care

Section C: Impact of e-learning in

dental education

8. Remember the days in the old school yard: from lectures to online learning

9. An intricate web - designing and authoring a web-based course

10. The many faces of interaction

11. Supporting the learner and teacher online

12. Making a mark - taking assessment to technology

13. Continuing professional development and ICT: target practice

14. Assuring quality

Section D: A connected future

15. Nine years of DentEd: a global perspective

16. A vision of dental education in the third millenium

\section{INTRODUCTION}

Information and communication technology (ICT) has already had an impact on teaching and learning at all levels of dental education - undergraduate, postgraduate and continuous professional development (CPD) - for both dentists and dental care professionals (DCPs). It may be that, in future, the impact of ICT will be greatest in postgraduate and continuing education. This is because undergraduates/trainee DCPs represent a relatively small proportion of all dental professionals and their teachers are hard pressed to provide education and training for these students at a time of dynamic growth in the demand for postgraduate and continuing education.

For some years, the General Dental Council (GDC) has monitored the

Visiting Professor, UCL Eastman Dental Institute, 256 Gray's Inn Road, London, WC2 1HH/Honorary Professor, University of Kent; ${ }^{2}{ }^{2}$ Professor of Dental Education Centre for Flexible Learning in Dentistry, King's College Dental Institute, Floor 3, Strand Bridge House, 138-142 Strand, London, WC2 $1 \mathrm{HH}$

${ }^{*}$ Correspondence to: Professor P. A. Reynolds Email:P.A.Reynolds@kcl.ac.uk

Refereed Paper

DOI: $10.1038 /$ sj.bdj.2008.622

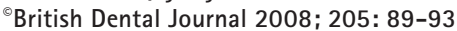

requirement for all registered dentists to undertake and record 250 hours of CPD over each five-year cycle, with at least 75 of the hours spent undertaking verifiable CPD. ${ }^{1}$ From 31 July 2008, the compulsory requirement to undertake and record CPD will also apply to all DCPs. ${ }^{2}$

A consequence of these changes is that there has been (and will continue to be) an increasing demand for CPD and also for postgraduate programmes leading to Masters degrees in a range of dental specialties. To meet this demand there is a need for a new approach to the development and provision of suitable courses. It may be argued that expanding the current provision will suffice, but this ignores not just the rapid increase in demand, but also the opportunities that are now available as a result of advances in the use of ICT in distance learning.

\section{VARIETY OF OPTIONS}

Distance learning is not new to dentistry; already a number of postgraduate and CPD courses are available in this format. The advent of ICT systems has brought greater flexibility to the delivery of all levels of dental education and to the learning process. Systems and services such as videoconferencing 
and CD-ROMs are revolutionising the delivery of dental education by potentially reducing the amount of paper (and the cost of delivery), by retaining the personal touch without the necessity of bringing people together in the same physical location and by making it possible for more dentists and DCPs to take part in postgraduate and continuing education.

With a certain amount of freedom and flexibility about how CPD hours are accumulated, the options are increasingly varied, ranging from online 'webinars' (real time seminars delivered via the world wide web) to fully online Masters degree programmes. Most fall into the hybrid category and use a mix of print, electronic resources and face-to-face teaching. The challenge now is to take things at least one stage further by using the potential of the Internet to offer fully online courses as the mainstream method of providing CPD and an increasing proportion of postgraduate education.

CPD hours can be earned through a variety of learning activities other than standard attendance courses, all of which can contribute to the accumulation of the necessary hours. There are many examples, two of which are:

- CPD quizzes with an online input such as those offered by the British Dental Journal/UCL Eastman Dental Institute, Primary Dental Care, Team in Practice, Dental Update and other journals

- Short learning modules such as those provided by CPD-HQ, a company founded by the School of Dentistry at Birmingham University to deliver verifiable CPD to all dentists via the internet. ${ }^{3}$ Their modules have a value of one hour of CPD and have titles such as 'Clinical case - B.C: mobility of teeth.' The modules are fully interactive with quizzes, scores and notes.

\section{COURSEWORK}

Apart from the 'explosion' in CPD, there has also been a vast increase in the number of dental postgraduate programmes leading to the award of certificates, diplomas or degrees (usually at Masters level). In the past, such

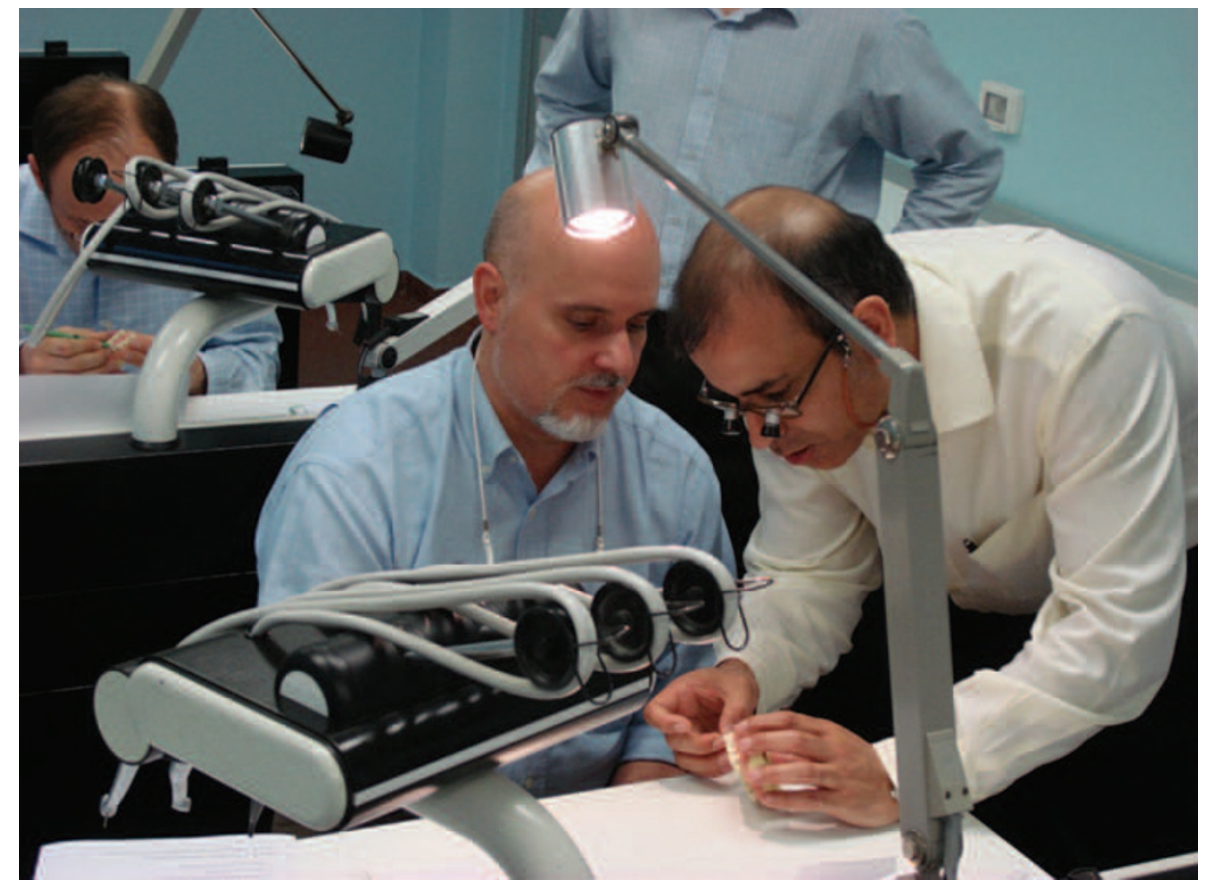

Fig. 1 Hands-on component of a blended learning CPD course on anterior aesthetics

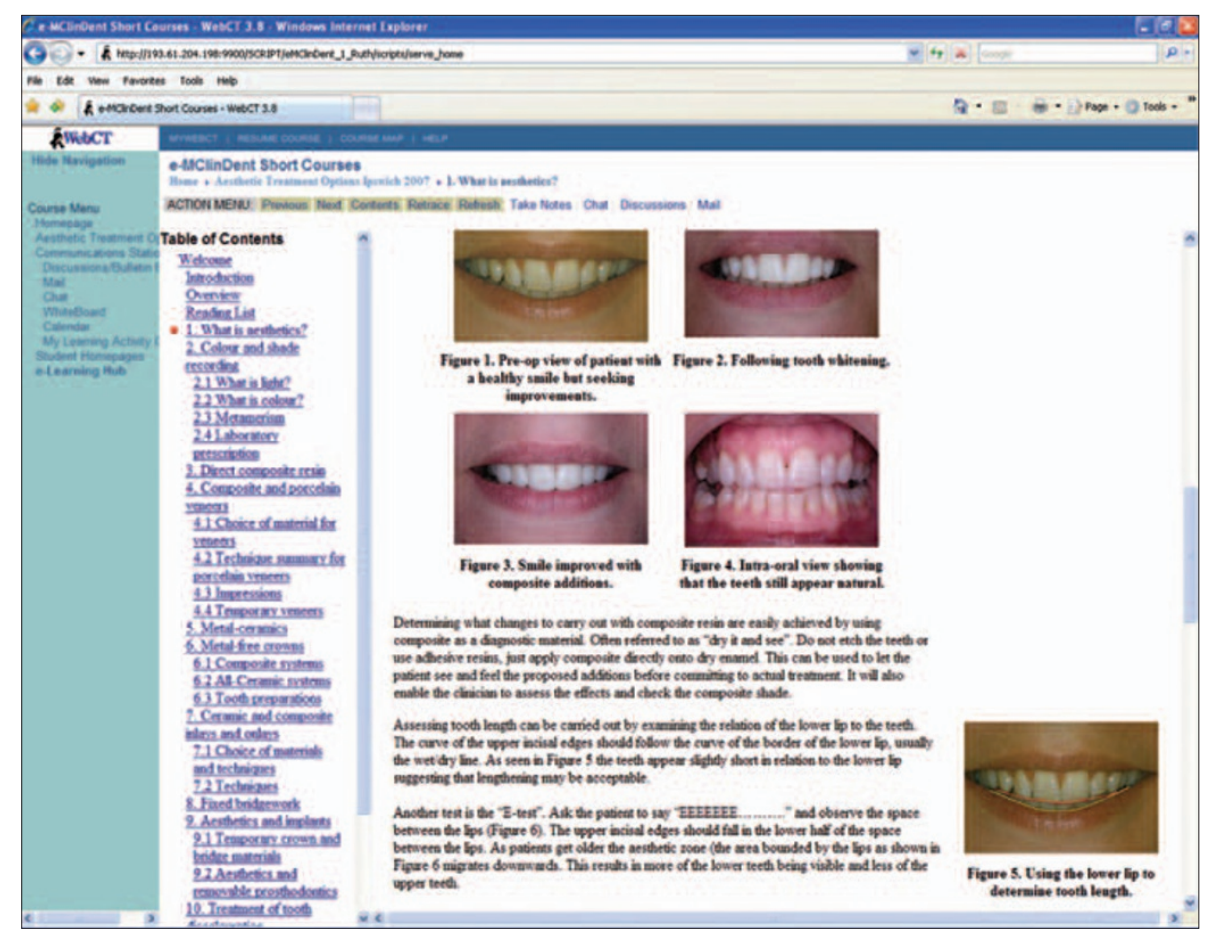

Fig. 2 Screen shot of the VLE online component of the blended learning CPD course on anterior aesthetics, showing the pedagogical tools in the left hand column and the e-content on the right

programmes have generally been run as full-time, attendance courses. As such they have found it difficult to attract busy general dental practitioners who find it difficult to spend much time away from their practices. Apart from those offered exclusively by dental schools, it is therefore perhaps unsurprising that a number are run by the Faculty of General Dental Practice (UK) or as collaborations between the Faculty and individual dental schools. Diploma and Masters programmes are increasingly based on blended learning and involve participants in a series of short, face-toface attendance courses (Fig. 1), which are typically of between one and five days duration and are linked to practicebased clinical work, home-based written assignments and the production of a dissertation (report). All these activities can to a greater or lesser extent be supported 
by ICT, including: emailing assignments; looking at websites; attending lectures by videoconferencing or seeing them later as a webcast; gathering information via the Internet; and interacting with tutors and fellow students. All are valuable new additions to the learning experience.

In fully online programmes or courses, all these resources are combined in a structured rather than an $a d$ hoc way to provide integrated courses. The benefits for dental practitioners and DCPs include:

1. The ability to acquire new skills and qualifications that were not included in undergraduate or initial training

2. The ability to acquire advanced skills and knowledge in specific disciplines within dentistry

3. The opportunities for DCPs to work alongside and learn with general dentists and specialists.

For postgraduates, online learning enables them to "pursue an interest in obtaining a postgraduate qualification' and/or 'open up new career opportunities in teaching or research in that speciality'. ${ }^{4}$

The ability of e-learning to aid the achievement of such aims is considerable, but on its own, there is no guarantee that it will provide a better teaching andlearning environment. Asthe website of one CPD provider claims: 'Quality e-learning is not just about exploiting computer power, it must include educational expertise and an awareness of the strengths and limitations of this approach to lifelong learning. ${ }^{3}$

However, these caveats have not stopped the development of online courses, whether of the hybrid or fully online type. Both postgraduate and CPD modules are available and it is predicted that the number will grow as their benefits are better recognised and understood.

\section{VIRTUALLY THERE}

As previously described, ${ }^{5}$ in the wider world, at the core of online education, it is increasingly likely to find a virtual learning environment (VLE) for students to enter and access a wide range of teaching and learning resources (Fig. 2). In the VLE, the course differs

\begin{tabular}{|c|c|}
\hline Standard classroom & Virtual classroom \\
\hline Textbook & Online publications and e-books \\
\hline Chalkboard & Interactive whiteboard \\
\hline Pen and paper & PC \\
\hline Overhead projector & Visualiser \\
\hline Lectures and tutorials & Videoconferencing and webcasts \\
\hline Personal interaction & $\begin{array}{l}\text { Email, chatrooms, bulletin boards, } \\
\text { online and one-to-one tutorials }\end{array}$ \\
\hline
\end{tabular}

from user-initiated, independent access to online material because it has an instructor and a registered group of participants. Within the VLE there can be a virtual classroom that brings together a teacher and students and enables them to interact with each other. Once they have accessed the classroom, students can listen to lectures, participate in exercises, ask questions and receive feedback just as they would in a conventional classroom. This is now being extended through the VLE 2.0 approach which allows even greater access to pedagogical tools and interactive resources and content. ${ }^{6}$

In a normal classroom, there are a number of teaching aids and procedures that can be replicated in the virtual equivalent (Table 1). The ability of the Internet to link all these together into a powerful teaching and learning infrastructure is enhanced by the ability these virtual aids have to perform a far wider range of tasks than their traditional counterparts.

\section{TRAINING THE TRAINERS}

Both teachers and students have to adapt to the world of technology. The former can be too set in their ways or be 'technophobic', or may be unwilling to change their teaching methods. To be effective in the e-learning environment, teachers need to understand the potential of ICT and their own ability to maximise this potential.

It has recently been suggested that 'Evidence from the literature has shown that teachers' uses of ICT are affected by the types of resources available to them, the training they have had, their expertise in using ICT, and their understanding of the relevance of ICT to their curriculum. ${ }^{7}$ This can mean that some teachers will only use the forms of ICT with which they are familiar. There is therefore an ongoing need for 'training the trainers'.

This entails knowing not just how a computer works, but also how it, and other ICT systems, can be applied to education; and how they can influence all aspects of teaching, including course design and content. In this context it has been suggested that 'Teacher training programmes not only need to prepare and support teachers in the appropriate choices and uses of ICT environments, they also need to challenge teachers' fundamental beliefs about how to teach their subject and how specific ICT resources can enhance and fundamentally change the way in which their students learn.'

However, a study into the use of the StudyNet VLE at the University of Hertfordshire showed that academic staff may not be adverse to such an environment. ${ }^{9}$ This study indicated that 91\% of respondents from the staff used the University's VLE. As the majority of respondents were aged 44-50 years, it would also seem that age may not be a barrier.

The applications of the StudyNet, one example of a VLE, paint another picture in which its use seemed to be at a minimal level. Within the VLE, the most frequently used facilities were module information, news and teaching material (mainly lecture notes or PowerPoint presentations, and the uploading of reading lists). The authors interpret this as 
an example of a VLE being used mainly as an information source and administrative tool. ${ }^{9}$

These findings are borne out by a survey at King's College London (KCL) into the use of ICT for learning and teaching. ${ }^{10}$ They indicate that there was widespread use of common IT applications in teaching, such as standard PC applications, email, Internet and PowerPoint. However, in common with the University of Hertfordshire study, ${ }^{10}$ the KCL study suggested that the full potential of ICT for teaching and learning was not being realised.

Nevertheless, both studies revealed pointers to the way forward. One of the recommendations that arose was to move from an information tool to an integrated part of teaching and learning by distilling and disseminating examples of good practice. The KCL study went further by highlighting the additional development needs of the vast majority of staff, primarily in online pedagogy, materials development and to a lesser extent, general computing and programming skills. It also highlighted the fact that staff had not received any training to enable them to integrate online technologies into teaching. As the report stated, 'This was regarded as a significant barrier to the further development of ICT in teaching and learning at the College' as long as 'current use of online delivery in higher education remains interactive and experimental. ${ }^{10}$

The solution is to "train the trainers' so that they are not just comfortable using ICT, but are also skilled in its application to teaching and learning, and putting material online. As the report states: "while online learning may offer substantive pedagogy and delivery advantages to higher education, optimal delivery requires expertise in: programming, materials development, detailed pedagogy, technical support, outside the core competencies of many academics and higher education institutions. ${ }^{10}$

This begs the question whether it is right to expect teaching staff to be 'jacks of all trades and masters of none'. Experience in compiling online courses at one dental school has shown that the time taken can impinge greatly on teachers' time and other academic and

Table 2 Minimum computing specifications for online MClinDent (Fixed and Removable Prosthodontics) from King's College London

\begin{tabular}{|c|c|}
\hline PC specifications & Mac specifications \\
\hline IBM-compatible PC & G4 or higher; $500 \mathrm{MHz}$ minimum \\
\hline $\begin{array}{l}\text { Pentium } 4 \text { processor or higher; } 500 \mathrm{MHz} \text { minimum; } \\
1 \mathrm{GHz} \text { recommended }\end{array}$ & 512MB RAM minimum \\
\hline 200MB free space on hard disk minimum & $200 \mathrm{MB}$ free space on hard disk minimum \\
\hline $\begin{array}{l}\text { CD-ROM drive minimum; CD and DVD R/W drive } \\
\text { recommended }\end{array}$ & $\begin{array}{l}\text { CD-ROM drive minimum; } C D \text { and DVD R/W drive } \\
\text { recommended }\end{array}$ \\
\hline Windows XP SP2 or Windows Vista & OS 10.3 or higher recommended \\
\hline $\begin{array}{l}\text { Screen resolution } 800 \times 600(1,024 \times 768 \text { recom- } \\
\text { mended })\end{array}$ & $\begin{array}{l}\text { Screen resolution } 800 \times 600(1,024 \times 768 \text { recom- } \\
\text { mended })\end{array}$ \\
\hline Sound card and speakers & Sound and speakers \\
\hline $\begin{array}{l}\text { Internet access and email account (broadband } \\
\text { essential) }\end{array}$ & $\begin{array}{l}\text { Internet access and email account (broadband } \\
\text { essential) }\end{array}$ \\
\hline Internet Explorer 6 or higher; Firefox 1.5 or higher & Firefox 2.0; Safari 3 \\
\hline Sun Java 1.5.0_7 recommended & Java for Mac OS 10 \\
\hline Adobe Reader 7 or higher & Adobe Reader 7 or higher \\
\hline RealPlayer 10 or higher & RealPlayer 10 minimum \\
\hline Macromedia Shockwave Player 10 or higher & Macromedia Shockwave Player 10 or higher \\
\hline QuickTime 6 or higher & QuickTime 6 or higher \\
\hline Adobe (Macromedia) Flash Player 8 or higher & Adobe (Macromedia) Flash Player 9 or higher \\
\hline $\begin{array}{l}\text { Microsoft Office } 2003 \text { or higher; or a compatible } \\
\text { office suite capable of reading and creating Word } \\
\text { documents }\end{array}$ & $\begin{array}{l}\text { Microsoft Office or a compatible office suite capa- } \\
\text { ble of reading and creating Word documents }\end{array}$ \\
\hline
\end{tabular}

clinical activities. Perhaps the solution is to realise that the development of online courses requires a range of skills drawn from academia, web design and ICT. ${ }^{10}$

\section{PROFESSIONAL LEARNERS}

Students, not all of whom are 'technoliterate', also have to adapt to the online world, although in 2002 one survey estimated that $90 \%$ of undergraduates, at the institution concerned, came from homes with computers and that this presupposed that they had some familiarity with computing and ICT. ${ }^{10}$

This may be an encouraging finding, as 'Many have claimed that in future an individual's ability to manage their own learning is also seen as a critical attribute for effective lifelong learning. It has also been claimed that ICT can make a distinctive and effective contribution to the development and support of continuous learning. ${ }^{11}$
Both the University of Hertfordshire and King's College London studies showed that, from the teaching perspective at least, the outcome for students was positive. In the former, teachers recognised their VLE's potential for more interactive work and greater student independence and autonomy in learning. ${ }^{9}$ In the latter, $80 \%$ of the academic staff who had taught online encountered no significant student resistance. ${ }^{10}$

Computers and suitable ICT learning facilities are available to undergraduate students in their universities and halls of residence. Nevertheless, large numbers also own personal laptop computers. The situation for those participating in CPD, or part-time postgraduate students, may be more difficult as for many dental courses they must have, or at least enjoy access to, relatively highspecification computing equipment. The specifications for an MClinDent (Fixed 
and Removable Prosthodontics) ${ }^{12}$ course are shown in Table 2. Although these are standard components it can, in some instances, entail a considerable financial outlay to purchase them.

It is also important that all students, whether at under- or postgraduate level or undertaking CPD, are familiar with ICT systems and services. As has recently been observed, 'students who are technologically illiterate tend to spend many hours trying to figure out how to use online technologies, communicate with instructors, submit online assignments, or download class-related material from the class website. ${ }^{13}$ Too much effort performing these tasks detracts from the main objectives of learning and completing the course.

Can it be assumed that as dentistry is a 'scientific subject' needing skills in using technology, its practitioners will be more attuned to the use of ICT? The answer may be yes, as a study of mature students of the Open University showed, perhaps not too surprisingly, that the use of ICT systems and services was more prevalent in its science and technology courses than for its arts subjects. ${ }^{14}$ However, it would be rash to claim that this finding will automatically be true for dentists and DCPs undertaking CPD or for postgraduate dental students.

There is no doubt that e-learners have to show greater discipline when studying outside the confines of a physical location. In addition, it has been suggested that the virtual learning environment leads to a lonely life for students. However, the results of a recent study counter this suggestion. It involved the uses of bulletin boards and demonstrated that "the majority of messages on the bulletin board were posted for the purpose of establishing personal contact. For example, finding a companion to study with was a particularly frequent topic among distance education students. ${ }^{15}$

Other common topics included suggestions for information about the subject administration and structure, which appeared among the bulletin postings within the first two weeks of term. In some cases, the online mode was used for seeking help with online technology including, for example, 'questions about downloading free software from the Internet for accessing online subject audio-visual data'. ${ }^{15}$

Nevertheless, a study of MBA students suggested that there may be isolation, as it found that learners at a distance often lack the social student network of the on-campus student, which provides them with a comparative perspective of their progress with the course. Feelings of inadequacy about learning can result in poor results and poor retention. During the study's interviews, many students re-iterated the importance of the group process to help them to continue to study, when the course became difficult, and in providing them with an on-going network of support. ${ }^{16}$ The same study also suggested that 'Learning collaboratively through group interaction was found to be achieved through the development of a group consensus of knowledge by communicating different perspectives, receiving feedback from other students and tutors, and discussing ideas until final negotiation was reached'. ${ }^{16}$

This paper has only considered developments in the UK and has not given any further consideration to the use of videoconferencing, webcasting or CD-ROMs in the delivery of CPD and postgraduate dental education, as they have already been covered in previous papers in this series. ${ }^{17-19}$

In conclusion it can be said that all stages of dental education will increasingly be dependent on the use of ICT and that because, in general, qualified dentists and DCPs live and work at locations distant to dental schools and other educational facilities, a significant proportion of their CPD and postgraduate courses will be delivered online. This trend will entail a change of approach to both teaching and learning.
1. General Dental Council. Continuing professional development and revalidation webpage. http:// www.gdc-uk.org/Our+work/Continuing + professio $\mathrm{nal}+$ development+and+revalidation/ (accessed 23 March 2008)

2. General Dental Council. Continuing professional development (CPD) for dental care professionals. London: GDC, 2008. http://www.gdc-uk.org/ NR/rdonlyres/D48927AD-831C-4240-9BE736F08BBAA9F1/77386/CPDforDCPs.pdf (accessed 23 March 2008).

3. CPD-HO website. http://www.cpd-hq.com (accessed 23 March 2008).

4. Eder A. Continuing education. Int J Comput Dent 2004; 7: 118-119.

5. Reynolds PA, Eaton K A, Mason R. Supporting the learner and teacher online. Br Dent J 2008; 204: 625-629.

6. Reynolds P A, Harper J, Mason R D, Cox M J, Eaton $K A$. An intricate web - designing and authoring a web-based course Br Dent J 2008; 204: 519-524.

7. Cox M. ICT and pedagogy: implications for international collaborative environments. Paper presented at ECOLECtESP 'Bridging visions for learning' conference, Charles University, Praque, Czech Republic 2004

8. Cox.M, Marshall G. Effects of ICT: do we know what we should know? Document transformation technologies CD-ROM. International Federation for Information Processing, World Computers in Education Conference, Stellenbosch, South Africa, 2-5 July 2004.

9. Thornton $M$, Jefferies $A$, Jones I, Alltree J, Leinonen E. Changing pedagogy: does the introduction of networked learning have an impact on teaching? Paper presented at the Networked Learning Conference, Lancaster University 2004

10. Observatory on Borderless Higher Education. Review of information and communication technology for learning and teaching at King's College, London. Online Learning: Institutional Review. London: King's College London, 2002.

11. Watson D, Downes T. Communications in an era of networks. In Watson D, Downes T (eds) Communications and networking in education. Learning in a networked society. New York: Kluwer Acacdemic Publishers, 2000.

12. King's College London Dental Institute. Programme requirements: minimum computer specification. MClinDent Fixed and removable Prosthodontics webpage, 2008. http://www.kcl.ac.uk/schools/ dentistry/pg/distance/pcspec.html (accessed 25 May 2008).

13. Miltiadou M, Savente W C. Applying social cognitive constructs of motivation to enhance student success in online distance learning. Educ Technol Rev 2002; 11: 78-95

14. Kirkwood A. Understanding independent learners' use of media technologies. Open Learning 2003; 18: 155-175.

15. Hellstén M. 'Anybody out there a real expert?'

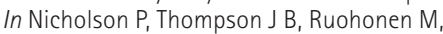
Multisilta J (eds) E-training practices for professional organizations. New York: Kluwer Academic Publishers, 2005.

16. Stacey E. Collaborative learning in an online environment. Can J Distance Educ 1999; 4: 14-33.

17. Reynolds P A, Eaton K A, Mason R. Seeing is believing: dental education benefits from developments in videoconferencing. Br Dent J 2008; 204: 87-92

18. Reynolds P A, Mason R, Eaton K A. Webcasting: casting the web more widely. Br Dent J 2008; 204: 145-149.

19. Eaton K A Reynolds P A Cox M J. Top of the pops - CD-ROM and DVDs in dental education. Br Dent J 2008; 204: 203-207. 